\title{
DISCUSSION
}

\section{Effect of mean grain size on shear modulus degradation and damping ratio curves of sands}

\author{
KRIPA UPRETI*, ENG-CHOON LEONG $†$ and CHRISTOS VRETTOS
}

\begin{abstract}
Contribution by Christos Vrettos
The general formulation of the title motivated the discusser to take a closer look into the details of the analysis presented in the paper (Upreti \& Leong, 2021). The authors considered available empirical relationships and enhanced the database with their own cyclic triaxial tests and bender element tests. By incorporating results from other studies, they finally proposed design curves dependent both on the uniformity coefficient and mean grain size diameter. The subject has also been treated earlier in the comprehensive investigation by Wichtmann \& Triantafyllidis (2012), based on resonant column tests on a variety of sands with variation of the grain size distribution curves. That study clearly identified the uniformity coefficient as the main parameter affecting the strain dependence of the shear modulus degradation and damping ratio. This trend has been confirmed by resonant column test series carried out by the discusser, which are presented herein.
\end{abstract}

However, the form of the design equations (13) and (14) suggests an accuracy that is not attainable. There are several reasons for this.

(a) Combining results for small and intermediate strains derived from resonant column tests with those for large strains obtained from cyclic triaxial tests requires a presumed value for the Poisson's ratio, a quantity that also depends on the strain level and is difficult to determine.

(b) The accuracy of resonant column testing depends on the accuracy of the calibration procedure for the device, since shear modulus and damping are determined indirectly - that is, from the back-analysis of a vibrating system. Recent studies have shown that the inertia of the drive head may depend on frequency (Clayton et al., 2009). Moreover, the ideal smooth response curve of the specimen with a clear resonance peak is not always encountered.

(c) The definition of the shear strain amplitude in resonant column testing is not unique among the various studies, because of the inhomogeneity of the induced shear strain field in the cylindrical soil specimen. Different rules have been used over the years to define an appropriate equivalent radius that is conveniently specified as a fraction of the specimen radius, $r_{0}$

$$
\gamma_{\mathrm{eq}}=\alpha r_{0} \theta_{l} / l
$$

where $l$ is the specimen length; $\theta_{l}$ is the twist angle at the top of the specimen; and $\alpha$ is a suitable factor. If the average strain over the specimen volume is used, then $\alpha=2 / 3$. Another alternative is to equate the strain energy in the inhomogeneous field with its counterpart in an equivalent homogeneous field (Prange, 1981), which yields $\alpha$ around $0 \cdot 7$. The current recommendation by ASTM D4015 (ASTM, 2015) to use as average $\alpha=0.8$ is based on the suggestion by Chen \& Stokoe (1979) to set $\alpha=0.82$ for shear strain amplitudes below $0.001 \%$ and $\alpha=0.79$ at $0.1 \%$. These values were derived by a priori assuming suitable non-linear stress-strain relationships for a variety of soils. Hence, the shear strain indicated in the studies used by the authors to derive their equations may vary considerably ( $\alpha$ between 0.67 and $0 \cdot 8$ ). This applies both to shear modulus and damping ratio.

(d) Linking $D(\gamma)$ to $G(\gamma) / G_{0}$ at given $\gamma$ contaminates $D(\gamma)$ with the inaccuracies of $G(\gamma) / G_{0}$, although $D(\gamma)$ is determined by an independent method.

In conclusion, inaccuracies associated with the above points overshadow the sound statistical analysis presented by the authors.

Experimental evidence derived from a resonant column test series by the discusser are used next to support the trend observed that the mean diameter $d_{50}$ plays only a minor role compared to $C_{\mathrm{u}}$. The tests comprise three sands $\mathrm{S} 2, \mathrm{~S} 3$ and $\mathrm{S} 4$, with the properties summarised in Table 6.

The test series was aimed primarily at refining the calibration procedure and data reduction of a Stokoe-type fixed-free apparatus in order that the derived shear modulus and damping ratio would be largely independent of the specimen size. For conciseness, the discusser reproduces herein only results for $G(\gamma) / G_{0}$. For the equivalent strain, the ASTM D4015 (ASTM, 2015) recommendation was followed, with $\alpha=0 \cdot 8$. Results from multi-stage tests at the highest confining stress of $400 \mathrm{kPa}$ on specimens of different size with length twice the diameter are shown for the three sands (S2, S3 and S4) in Fig. 11. It is possible to identify the inevitable, even small, scatter in the data, which is due to the inherent inaccuracies of the device calibration and measurement procedure. The curves calculated from the predictive equations (13) and (14) are also plotted for comparison, showing generally a good agreement. For a closer look, the shear strain amplitudes corresponding to $G / G_{0}=0.7$ are compared. The respective values $\gamma_{0 \cdot 7}$ are given in Table 7 .

It can be deduced that in the tests the influence of $d_{50}$ is not appreciable whereas the degradation of shear modulus is much stronger as the sand becomes more non-uniform. In other words, $\gamma_{0 \cdot 7}$ becomes gradually smaller as $C_{\mathrm{u}}$ increases from 1.5 to 1.7 to $2 \cdot 7$ for sands $S 3$ to $\mathrm{S} 2$ to $\mathrm{S} 4$, respectively. Equations (13) and (14) predict almost identical $\gamma_{0 \cdot 7}$ values for S3 and S4, although these two sands considerably differ in terms of uniformity; in the experiments the difference in response for these two sands is significant. 
Table 6. Properties of the sands in the resonant column tests, and target void ratio in the tests

\begin{tabular}{l|l|l|l}
\hline Description & S2 & S3 & S4 \\
\hline$d_{50}: \mathrm{mm}$ & 0.32 & 0.77 & 0.5 \\
$C_{\mathrm{u}}$ & 1.7 & 1.5 & 2.7 \\
$e$ & 0.788 & 0.70 & 0.64 \\
\hline
\end{tabular}
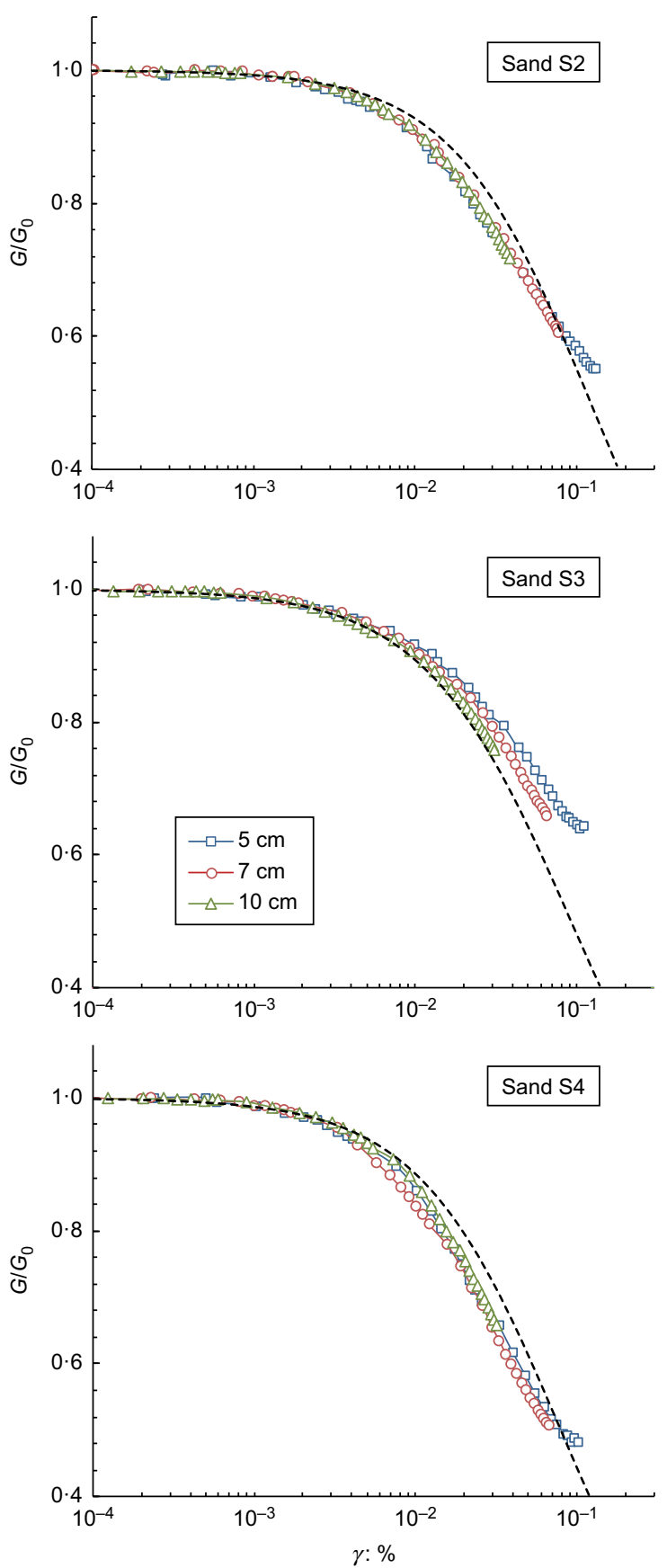

Fig. 11. Shear modulus reduction $G / G_{0}$ plotted against shear strain amplitude at the highest confining stress of $400 \mathrm{kPa}$ in multi-stage resonant column testing for the three sands and for the three specimen diameters. The dashed lines are for equations (13) and (14)

The observed behaviour in the tests is in accordance with the findings reported in the study by Wichtmann \& Triantafyllidis (2012). The same trend regarding $C_{\mathrm{u}}$ is reflected in the predictive equations by Menq (2003) and Senetakis et al. (2013).
Table 7. Shear strain amplitude at $G / G_{0}=0.7$ in multi-stage resonant column tests at confining stress of $400 \mathrm{kPa}$, and according to the predictive equations (13) and (14)

\begin{tabular}{l|c|c|c}
\hline \multirow{2}{*}{} & \multicolumn{3}{|c}{$\gamma_{0 \cdot 7}: \%$} \\
\cline { 2 - 4 } & S2 & S3 & S4 \\
\hline Equations (13) and (14) & 0.053 & 0.038 & 0.034 \\
Resonant column tests, Fig. 11 & 0.046 & 0.050 & 0.026 \\
\hline
\end{tabular}

For the damping ratio, the discusser refrains from any comparison as the predictive equations are too complex for the application and - as mentioned above - they include all the inaccuracies of the shear modulus reduction relationships.

Concluding and with no intention to diminish the merits of the study, the incorporation of both $d_{50}$ and $C_{\mathrm{u}}$ pretends an accuracy that is effectively not given; it is also not necessary when considering the variability of soil and the inherent inaccuracy in soil testing and data reduction. For all practical purposes, it is sufficient to consider the confining stress and the uniformity coefficient as the primary factors affecting the shear modulus degradation and damping ratio of sands.

\section{Authors' reply}

The authors would like to thank the discusser for his interest in this work and his thought-provoking contribution. This work looks at improving existing empirical relationships for estimating shear modulus degradation and damping ratio curves of sands. The influence of the uniformity coefficient $C_{\mathrm{u}}$ on the shear modulus degradation and damping ratio curves has been more widely reported compared to the effect of the mean particle size $d_{50}$ on the curves. The discusser has focused on the shear modulus degradation curve. The authors fully agree with the reasons given by the discusser regarding the accuracy of the tests in deriving shear modulus degradation curve, but this should not be the reason for not making improvements to estimate the shear modulus degradation curve.

The discusser shows shear modulus degradation curves obtained for three sands (S2, S3 and S4) using a Stokoe-type fixed-free resonant column device (Fig. 11). The effect of specimen size on the shear modulus degradation curves reinforces the discusser's comment on the accuracy of the tests. Fig. 11 shows specimen size to affect S3 more than the other two sands. Nevertheless, the authors thank the discusser for demonstrating that the shear modulus degradation curves obtained using equations (13) and (14) show good agreement with the resonant column test results. However, the discusser pointed out in Table 7 the differences in shear strain amplitude corresponding to $G / G_{0}=0 \cdot 7$ (i.e. $\gamma_{0.7}$ ) between that using equations (13) and (14), and the test data. Based on Table 7 , the discusser deduced that the influence of $d_{50}$ is not appreciable compared to $C_{\mathrm{u}}$. The discusser further pointed out that the behaviour of the three sands agrees with the findings reported by Wichtmann $\&$ Triantafyllidis (2012), and the trend that $\gamma_{0.7}$ decreases as $C_{\mathrm{u}}$ increases is reflected in the predictive equations of Menq (2003) and Senetakis et al. (2013).

For a better understanding of the accuracy of the existing predictive equations, the authors have included $\gamma_{0 \cdot 7}$ from the predictive equations of Menq (2003) and Senetakis et al. (2013) in Table 8. For each sand, equations (13) and (14) gave $\gamma_{0.7}$ values that are in closer agreement with the $\gamma_{0.7}$ values of the resonant column tests shown in bold compared to 
Table 8. Comparison of shear strain amplitudes at $G / G_{0}=0.7$ from various authors for sands $\mathrm{S} 2, \mathrm{S3}$ and $\mathrm{S} 4$

\begin{tabular}{l|c|c|c}
\hline \multirow{2}{*}{ Source } & \multicolumn{3}{|c}{$\gamma_{0 \cdot 7}: \%$} \\
\cline { 2 - 4 } & $\mathrm{S} 2$ & $\mathrm{~S} 3$ & $\mathrm{~S} 4$ \\
\hline Equations (13) and (14) & $0 \cdot 053$ & $0 \cdot 038$ & $0 \cdot 034$ \\
Resonant column tests, Fig. 11 & $\mathbf{0 \cdot 0 4 6}$ & $\mathbf{0 \cdot 0 5 0}$ & $\mathbf{0 \cdot 0 2 6}$ \\
Menq (2003) & $\begin{array}{l}0 \cdot 066 \\
0 \cdot 072 \\
\text { Senetakis } \text { et } \text { al. } \text { (2013) }\end{array}$ 0.060 & $0 \cdot 065$ & $0 \cdot 039$ \\
\hline
\end{tabular}

Menq (2003) and Senetakis et al. (2013). Considering the trend of the test data that shows $\gamma_{0.7}$ decreasing as $C_{\mathrm{u}}$ increases in the order S3 to S2 to $\mathrm{S} 4$, the different trend showed by equations (13) and (14) is because the $\gamma_{\mathrm{r}}$ given by equation (13) contains a linear combination of terms in $d_{50}$ and $C_{\mathrm{u}}$ and since $\mathrm{S} 3$ has the smallest $C_{\mathrm{u}}$ but the largest $d_{50}$ among the three sands, there is a 'compensating' effect that cannot be expected from Menq (2003) and Senetakis et al. (2013), which do not account for $d_{50}$. It is pointed out that the resonant column test data reported by Wichtmann \& Triantafyllidis (2012) do show an effect of $d_{50}$ on the shear modulus degradation curve when $C_{\mathrm{u}}$ is held constant. For a more reasonable comparison on the trend of $\gamma_{0 \cdot 7}$, only sands where either $C_{\mathrm{u}}$ or $d_{50}$ is changing or where both $C_{\mathrm{u}}$ and $d_{50}$ are changing in the same direction should be examined. In this respect, the $\gamma_{0 \cdot 7}$ trend shown by $\mathrm{S} 2$ and $\mathrm{S} 4$ should only be considered, as $\mathrm{S} 2$ has smaller $d_{50}$ and $C_{\mathrm{u}}$ than $\mathrm{S} 4$. In this comparison, they all (equations (13) and (14), Menq (2003) and Senetakis et al. (2013)) show the same $\gamma_{0 \cdot 7}$ trend as the test data.

For practical purposes, a simple predictive equation requiring fewer tests to obtain the parameters is most useful. Equations (13) and (14) use $d_{50}$ and $C_{\mathrm{u}}$, which are obtained from the grain size distribution curve that is needed by predictive equations using only $C_{\mathrm{u}}$. Equations (13) and (14) do show that a more accurate estimate of $\gamma_{0 \cdot 7}$ is obtained for S2, S3 and S4 compared to Menq (2003) and Senetakis et al. (2013). The interaction effect of various factors on the shear modulus degradation curve is complicated and none of the existing predictive equations can account for all the factors and give good agreement for all sands. One important point made by the discusser indirectly is that one should not use such an empirical equation to determine trend, as accuracy in estimating the shear modulus degradation curve of a sand does not necessarily equate to correctness in trend when examining across different sands. To compare behaviours of different sands, the experimental data should be used and the test method by which the experimental data is obtained should be scrutinised.

The authors would also like to take the opportunity to correct typographical errors in Figs 9(d), 9(e) and 10(b) of the paper. The $\sigma^{\prime}$ should be indicated as $\sigma^{\prime}=45 \mathrm{kPa}, \sigma^{\prime}=100 \mathrm{kPa}$ and $\sigma^{\prime}=62 \mathrm{kPa}$ instead of $\sigma^{\prime}=588 \mathrm{kPa}, \sigma^{\prime}=200 \mathrm{kPa}$ and $\sigma^{\prime}=79 \mathrm{kPa}$ in Figs 9(d), 9(e) and 10(b), respectively.

\section{REFERENCES}

ASTM (2015). D4015-15e1: Standard test methods for modulus and damping of soils by fixed-base resonant column devices. West Conshohocken, PA, USA: ASTM International.

Chen, A. T. F. \& Stokoe, K. H. II (1979). Interpretation of strain-dependent modulus and damping from torsion soil tests, Rep. No. USGS-GD-79-002, NTIS No. PB298749. Menlo Park, CA, USA: U.S. Geological Survey.

Clayton, C. R. I., Priest, J. A., Bui, M. T., Zervos, A. \& Kim, S. G. (2009). The Stokoe resonant column apparatus: effects of stiffness, mass and specimen fixity. Géotechnique 59, No. 5, 429-437, https://doi.org/10.1680/geot.2007.00096.

Menq, F. Y. (2003). Dynamic properties of sandy and gravelly soils. PhD dissertation, University of Texas, Austin, TX, USA.

Prange, B. (1981). Resonant column testing of railroad ballast. In Proceedings of the 10th international conference on soil mechanics and foundation engineering, vol. 3, pp. 273-278. Rotterdam, the Netherlands: A.A. Balkema.

Senetakis, K., Anastasiadis, A. \& Pitilakis, K. (2013). Normalized shear modulus reduction and damping ratio curves of quartz sand and rhyolitic crushed rock. Soils Found. 53, No. 6, 879-893.

Upreti, K. \& Leong, E. C. (2021). Effect of mean grain size on shear modulus degradation and damping ratio curves of sands. Géotechnique 71, No. 3, 205-215, https://doi.org/10.1680/jgeot. 18.P.169.

Wichtmann, T. \& Triantafyllidis, T. (2012). Effect of uniformity coefficient on $G / G_{\max }$ and damping ratio of uniform to wellgraded quartz sands. J. Geotech. Geoenviron. Engng. 139, No. 1, $59-72$. 